\title{
1 Seed dispersers help plants to escape global warming
}

2 Juan P. González-Varo, José V. López-Bao and José Guitián

3 J. P. González-Varo (jpg62@cam.ac.uk), Conservation Science Group, Department of

4 Zoology, University of Cambridge, David Attenborough Building, Cambridge, UK. JPGV

5 also at: Integrative Ecology Group, Department of Integrative Ecology, Estación Biológica

6 de Doñana (EBD-CSIC), Sevilla, Spain. - J. V. López-Bao, Research Unit of Biodiversity

7 (UO/CSIC/PA), Oviedo University, 33600 Mieres, Spain. - J. Guitián, Departamento de

8 Bioloxía Funcional, Facultade de Bioloxía, Universidad de Santiago de Compostela (USC),

$9 \quad$ Santiago de Compostela, Spain.

10 All authors equally designed the study, analysed the data and wrote the manuscript.

11

12 
14 Plants are shifting their ranges towards higher elevations in response to global warming, yet such shifts are occurring at a rate slower than is needed to keep pace with a rapidly changing climate. There is, however, an almost complete lack of knowledge on seed dispersal across altitude, a key process to understand what constrains climate-driven range shifts. Here, we report the first direct empirical evidence on altitudinal seed dispersal mediated by two common frugivorous mammals: the red fox Vulpes vulpes and the pine marten Martes martes. We conducted a 3-year (bait-marking) experiment in a mountainous region of Spain. We offered experimental fruits containing colour-coded seed mimics at feeding stations that simulated source trees. The colour codes allowed us to identify the exact origin of seed mimics found later in mammal scats. Nearly half $(47 \%)$ of the dispersal events occurred towards higher elevations, despite only ca. $25 \%$ of the study area being above the average altitude of the feeding stations (1344 m). Seeds dispersed uphill gained an average of $106 \mathrm{~m}$ $($ median $=111 \mathrm{~m})$ and a maximum of $288 \mathrm{~m}$, greatly exceeding the estimated requirements to escape warming (35.4 m per decade). Yet, foxes mediated much more uphill seed dispersal than martens ( $57 \%$ and $26 \%$ of dispersal events, respectively), which can be explained by between-disperser differences in home range size and habitat specificity. Dispersers with larger home ranges move farther and potentially disperse more seeds to higher altitudes, while habitat generalism is necessary to transport seeds above vegetation belts delimiting contrasting habitat types. We discuss how both traits (home range size and habitat specificity) can be used to infer altitudinal seed dispersal across disperser species and mountainous landscapes. 
38 As a result of global warming, many plant and animal species are shifting their ranges worldwide, generally moving towards the poles and higher altitudes (Parmesan 2006, Chen et al. 2011, Devictor et al. 2012, Lenoir and Svenning 2015). A critical question is whether species will be able to disperse fast enough to track their suitable climatic ranges (Pearson 2006, Jump et al. 2009, Ozinga et al. 2009, Chen et al. 2011, Devictor et al. 2012, Schloss et al. 2012, Cunze et al. 2013). Answering this question is key for both predicting the impacts of global warming on ecosystems and understanding the role of dispersal limitation in determining novel communities (Ozinga et al. 2009, Schloss et al. 2012).

Plants are sessile organisms and seeds (or spores in ferns) constitute the unique mobile stage during the life of individuals. Given the long seed dispersal distances required to track climate change in latitude (Hampe 2011, McConkey et al. 2012, Corlett and Westcott 2013, Cunze et al. 2013), altitudinal migration in mountainous regions has been suggested to be the most feasible shortcut to keep pace with rapidly changing climate (Colwell et al. 2008, Jump et al. 2009): an altitudinal shift of $100 \mathrm{~m}$ corresponds, in climatic terms, to roughly a 100-km shift in latitude (Colwell et al. 2008). A recent global meta-analysis of observed range shifts found a median altitudinal increase of $16.0 \mathrm{~m}$ per decade in plants, less than half the estimated $35.4 \mathrm{~m}$ per decade needed to track rising temperatures (Chen et al. 2011). Nonetheless, empirical evidence on altitudinal seed dispersal has been completely lacking until recently, when Naoe and colleagues (2016) inferred - through an indirect, isotope-based method - extensive uphill seed dispersal (hundreds of meters) in the cherry tree Prunus verecunda in Japan. Although other approaches, such as transplant experiments, can help us to infer the presence or absence of dispersal limitation (Lee-Yaw et al. 2016), knowledge of the seed dispersal process is essential to understand the observed range shifts and predict

61 future changes (Neilson et al. 2005, Hampe 2011). 
Many plants across the world's biomes depend on animals to disperse their seeds

(Jordano 2013). Their ability to reach higher altitudes will ultimately depend on the movement patterns of the disperser species they interact with (Jordano et al. 2007, GonzálezVaro et al. 2013). During the last decade there have been significant advances in our understanding of seed dispersal distances in the horizontal plane mediated by different animal taxa (Jordano et al. 2007, Spiegel and Nathan 2007, González-Varo et al. 2013, PérezMéndez et al. 2016). For example, we know that many bird and mammal species regularly disperse seeds at distances ranging from a few hundred meters to a few kilometers (Jordano et al. 2007, Spiegel and Nathan 2007, González-Varo et al. 2013). However, seed dispersal in the vertical axis, such as when dispersers occur in a mountainous region, remains an issue. We therefore asked the question: do seed dispersers help plants by providing the estimated elevational displacements they need to track their suitable climatic ranges?

Here we provide the first direct (i.e. non-correlational) empirical evidence of altitudinal seed dispersal mediated by animals. We used an exceptional dataset resulting from a 3-year field experiment carried out in a mountainous landscape in NW Spain, which aimed at measuring seed dispersal events mediated by two common and widespread mammals: the red fox (Vulpes vulpes, Canidae) and the pine marten (Martes martes, Mustelidae). Foxes occur in North America, Eurasia, North Africa and Australia (non-native species), while martens occur in Europe and Western Asia (Wilson and Mittermeier 2009). Both mammals are important generalist frugivores and legitimate seed dispersers of many fleshy-fruited species across plant communities, i.e. they transport seeds in their guts and defecate them in conditions that are suitable for germination in different habitats and landscapes (Herrera 1989, De Marinis and Masseti 1995, Rosalino and Santos-Reis 2009, López-Bao and González-Varo 2011, López-Bao et al. 2015). Our field (bait-marking) experiment consisted of offering fruits containing colour-coded seed mimics to these mammals, at feeding stations 
simulating source trees. The exclusive colour code of each simulated source tree allowed us to locate the exact origin of seed mimics found later in fox and marten scats (González-Varo et al. 2013), thereby directly measuring altitudinal seed dispersal using geo-referenced information. Furthermore, we explore, for the first time, relationships between horizontal $(x$, $y$ ) and altitudinal $(z)$ seed dispersal distances, and show the importance of habitat generalism for dispersing seeds from forest habitats to deforested mountaintops.

\section{Methods}

We measured altitudinal seed dispersal events of fleshy-fruited species mediated by foxes and martens by means of a 3-year bait-marking experiment carried out in the Devesa da Rogueira forest, located in Serra do Courel $\left(42^{\circ} 37^{\prime} \mathrm{N}-7^{\circ} 05^{\prime} \mathrm{W}\right)$, a mountainous region (ca. $\left.250 \mathrm{~km}^{2}\right)$ in NW Iberian Peninsula. The study site had 22\% of area below $1000 \mathrm{~m}$ a.s.1., $60 \%$ between 1000 and $1400 \mathrm{~m}$, and $18 \%$ above $1400 \mathrm{~m}$ a.s.1.. Percentages were calculated using QGIS v. 2.14.0 (Quantum GIS Development Team 2015) within a circle of 4-km radius centred in the study area. Forest occupies approximately $50 \%$ of the territory in the study region and is usually restricted to altitudes below $\sim 1400 \mathrm{~m}$ (Munilla et al. 2008). Detailed information on this experiment and the main characteristics of study area can be found in González-Varo et al. (2013). Briefly, we offered experimental fruits containing coloured seed mimics to the two mammal species in three different years $(2008,2009$ and 2010). We used figs of the common

Prunus spinosa (López-Bao et al. 2015)). In other mammal species (Asiatic black bears 
species and seed mimics (Koike et al. 2011). Therefore, we expect the dispersal events reported here to be representative of how foxes and martens disperse fleshy-fruited seeds naturally.

We prepared the experimental figs, using tweezers to embed the seed mimics in their pulp (10 seeds per fig). The baiting was carried out between September and October of each year, coinciding with the peak of the fruiting season of fleshy-fruited species in the study area (López-Bao and González-Varo 2011). Every September, we set up ‘feeding stations’ where we offered the experimental figs on the ground below the canopy of 'simulated fruiting trees' (Fig. S2). Each feeding station consisted of an area of $\sim 60 \mathrm{~m}^{2}$ with a total of six feeders (trays of $18 \times 12 \times 3 \mathrm{~cm}$; Fig. S1). We geo-referenced each feeding station using the centroid of the polygon generated by the spatial position of the six feeders. An exclusive colour code was assigned to the seed mimics offered at each feeding station. In this manner, we were able to directly identify the source (feeding station) of any seed mimics dispersed by foxes and martens, and subsequently found in their scats. We set up a total of eight feeding stations ( $n=$ 3, 6 and 6 feeding stations in 2008, 2009 and 2010, respectively), with distances between stations ranging between $280 \mathrm{~m}$ and $1760 \mathrm{~m}$ (Fig. S2; Table S1).

We offered a total of 1322 experimental figs $(13,220$ seed mimics $)$ during the 3 years of the experiment; on average, 165.3 figs per station. We monitored fruit removal from the feeding stations and searched for mammal scats twice a week from September to November in each of the three study years. We followed a sampling strategy that aimed to detect the longest dispersal events. This strategy consisted of (i) the intensive sampling within a 2-km radius around each feeding station, and (ii) additional sampling within a 1-km radius around the farthest seed dispersal event from each feeding station, until no more seed mimics were found in that extra buffer (see details in González-Varo et al. 2013). We searched for scats along a network of paths of $\sim 70-\mathrm{km}$ length over an area of $\sim 40 \mathrm{~km}^{2}$ (altitudinal range 600 
$1643 \mathrm{~m}$ a.s.1.), and accounting for an accumulated walking distance of $\sim 900 \mathrm{~km}$ during the study period (González-Varo et al. 2013). Previous studies have shown that the density of faeces of these mammals is much higher along paths than through the natural vegetation (Suárez-Esteban et al. 2013). We found and analyzed 2027 mammal scats during the whole study period (641 in 2008, 888 in 2009 and 498 in 2010). We found mammal scats containing seed mimics from all but one feeding station (7 out of 8), which was excluded owing to disturbance by wild boars (see Table S1). We recovered and geo-referenced 98 scats containing 665 seed mimics, 95 of which (containing 657 seed mimics) were identified to belong to red foxes or pine martens (Fig. S1). We also assigned a macrohabitat category to each scat, differentiating between forest and non-forest habitats. Remarkably, 9 of the 95 scats had seed mimics belonging to two different feeding stations (i.e. different colours; see Fig. S1): seven from red foxes and two from pine martens. Therefore, the 95 scats actually accounted for 104 seed dispersal events (i.e. 'source-scat' combinations), 70 and 34 mediated by red foxes and pine martens, respectively, which effectively constitute the sample size of this study. It is noteworthy that overall recapture rates were $\sim 5 \%$, which is above those obtained from bird ringing and within the range of those obtained in butterfly tagging; a discussion on the method can be found in González-Varo et al. (2013).

We tested for statistical differences between red foxes and pine martens in altitudinal seed dispersal using Mann-Whitney $U$ tests, and in their relative contribution to seed dispersal towards higher elevations using a Chi-square test. We also used a Chi-square test to assess differences between foxes and martens in their frequency of seed deposition in forest versus non-forest habitats. We tested whether there was a relationship between Euclidean $(x$, $y$ ) and altitudinal $(z)$ seed dispersal distance, and whether such a relationship differed between disperser species. For this analysis, we added a negative sign to the Euclidean distances belonging to dispersal events towards lower elevations, that is, to negative altitudinal 
dispersal distances. We used two linear models with altitudinal dispersal distance as the response variable and Euclidean distance as the explanatory variable. In one model we additionally included disperser species as an explanatory variable (fixed factor). The interaction between Euclidean distance and disperser species allowed us to test for differences between disperser species in the slopes through which they dispersed seeds altitudinally. We evaluated model fit according to $\mathrm{R}^{2}$ values and the Akaike Information Criterion (AIC) (Burnham and Anderson 2002). All analyses were performed using R v. 3.2.3 (R Development Core Team 2015).

\section{Results}

We offered the experimental fruits at elevations ranging between 1169 and $1395 \mathrm{~m}$ and subsequently found dispersed seeds between 831 and $1580 \mathrm{~m}$, a range 3.3 times larger (Fig. 1A). It is worth noting that the highest elevation point in the study area is at $1643 \mathrm{~m}$ a.s.1., just $63 \mathrm{~m}$ higher than the maximum altitude reached by the seed mimics. Nearly half of scats with seed mimics $(47.1 \%$; 49 out of 104$)$ were found at higher elevations than their respective source trees, gaining a median of $111 \mathrm{~m}($ mean $=106 \mathrm{~m})$ and a maximum of $288 \mathrm{~m}$ in altitude.

Altitudinal patterns of seed deposition differed between disperser species (Fig. 1). We found significant differences between foxes and martens in both the altitude of seed deposition (Mann-Whitney $U$ test: $P<0.001$; Table 1, Fig. 1A) and the altitudinal seed dispersal distance (Mann-Whitney $U$ test: $P=0.003$; Table 1, Fig. 1B). Indeed, the percentage of dispersal events towards higher elevations was more than two-fold higher in the red fox $(57.1 \%$; 40 out of 70 events) than in the pine marten $(26.5 \% ; 9$ out of 34 events $)$ (Chi-square test: $\chi^{2}=7.45, d f=1, P=0.006$ ) (Fig. 1B). Moreover, foxes deposited 57\% of 
scats (36 out of 63) in non-forest habitats (mainly heathlands), while martens only deposited $6 \%$ ( 2 out of 32$)$ in non-forest habitats, the vast majority (94\%) being found in forest habitats (Chi-square test: $\left.\chi^{2}=20.83, d f=1, P<0.001\right)$.

Finally, we detected a general positive and significant relationship between the Euclidean and the altitudinal dispersal distances (Table 2), indicating that seeds dispersed farther are more likely to reach both higher and lower elevations (Fig. 2). Yet, the slope of such relationship differed between disperser species, being two times steeper in the pine marten than in the red fox (Fig. 2). Indeed, the linear model incorporating the disperser species showed a better fit than the model that only included the Euclidean distance, in terms of both $\mathrm{R}^{2}$ and AIC (Table 2 ).

\section{Discussion}

Our results provide the first direct empirical evidence that seed dispersers can altitudinally disperse seeds to elevations that greatly exceed the estimated median $35.4 \mathrm{~m}$ (range: 8.3-56.7 m) per decade needed to track rising temperatures (Chen et al. 2011). We found that nearly half of the dispersal events observed were towards higher and colder places. This frequency of uphill seed dispersal is remarkable because area generally decreases with altitude and, in fact, only ca. $25 \%$ of the study landscape is above the average altitude of the feeding stations $(1344 \mathrm{~m})$. Considering the general decrease of temperature with elevation $\left(5.2-6.5^{\circ} \mathrm{C}\right.$ per $1000 \mathrm{~m})\left(\right.$ Colwell et al. 2008), the reported movements entail differences of up to $1.5-1.9^{\circ} \mathrm{C}$ mean temperature decrease in a single dispersal event ( $\max$. altitudinal distance $=288 \mathrm{~m}$ ). Importantly, seed dispersal upwards - as opposed to downwards - was constrained by the altitudinal limits of the study area (Fig. 1A, Fig. 2). Therefore, altitudinal dispersal distances above the maximum value reported here $(288 \mathrm{~m})$ would be expected without such constraint 
(e.g. higher mountains or dispersal from lower elevations). Whether fleshy-fruited plants will be able to migrate altitudinally at a proper velocity will depend on (i) the possibilities of recruitment above the current climatic range, and (ii) the time they need to reach the reproductive age. First, seeds dispersed above the currently suitable climatic range will find an unsuitable environment that is forecasted to be suitable in two or three decades. Dispersal towards climate microrefugia (i.e. areas that support locally favourable climates; Dobrowski 2011) may therefore be crucial. Second, many early successional species can reach the reproductive age in a few years, however, forest trees may require a few decades (1-4; Nathan et al. 2011). Our results provide basic information that could be used to understand the importance of both factors (i.e. habitat suitability and time lag until maturation age) on altitudinal range shifts at the community level, though this is beyond the scope of the present study.

Our findings add to the indirect evidence recently provided by Naoe et al. (2016) on altitudinal dispersal distances generated by Asiatic black bears and Japanese martens (Martes melampus). In their study, Naoe et al. (2016) found a negative correlation between altitude and the oxygen isotope ratios $\left({ }^{18} \mathrm{O}\right.$ and $\left.{ }^{16} \mathrm{O}\right)$ of Prunus verecunda seeds sampled from mother plants, then used the regression lines to estimate altitudinal seed dispersal. In our study, the possibility of linking horizontal and altitudinal dispersal distances (Fig 2), along with the distribution of the vegetation in our study area (i.e. deforested mountain tops; Fig. S3; see also López-Bao and González-Varo 2011) allowed us to disentangle two key traits that enable animal species to promote altitudinal seed dispersal: home range size and habitat specificity. First, home range size determines the spatial scale of seed dispersal patterns in the horizontal plane (Spiegel and Nathan 2007, González-Varo et al. 2013, Naoe et al. 2016, Pérez-Méndez et al. 2016) and, therefore, also in the vertical axis when the disperser's daily movements occur in mountainous regions (Fig. 2). Compared to animals with small home 
ranges, animals that frequently perform long displacements are expected to disperse more seeds towards higher elevations. Home range sizes are positively associated with the frequency of long-distance seed dispersal and, in general, with the disperser's body sizes (Harestad and Bunnel 1979, Spiegel and Nathan 2007, González-Varo et al. 2013, Naoe et al. 2016, Pérez-Méndez et al. 2016). These patterns hold for our study species (González-Varo et al. 2013): body weights in red foxes and pine martens are of $3-14 \mathrm{~kg}$ and $0.8-1.8 \mathrm{~kg}$, respectively, and their home ranges have 200-600 ha and 50-190 ha, respectively (Cavallini 1996, Dekker et al. 2001, Zalewski et al. 2004, Wilson and Mittermeier 2009, Moreno-Opo et al. 2015). Hence, larger animals move farther and potentially disperse more seeds to higher altitudes. The topographic features of the study area, with very steep slopes, lead to major altitudinal movements even when the Euclidean dispersal distances were relatively short $(<1$ $\mathrm{km}$; especially by pine martens). Yet, long-distance dispersal events (farther than $1 \mathrm{~km}$ ) were required to move up seeds above $200 \mathrm{~m}$ in altitude (Fig. 2). It is not difficult to envisage a much more important role of long-distance seed dispersal in mountainous regions with shallower slopes, where extensive horizontal movements are needed to gain a few meters in altitude. Our findings suggest that it is possible to infer altitudinal seed dispersal by combining topographical maps and available knowledge on horizontal seed dispersal distances. However, because such knowledge is very limited at the species level, within diverse disperser assemblages (Jordano et al. 2007), information on home-range size (more accesible at the species level; e.g. Dennis and Westcott 2007) can be used to infer maximum horizontal dispersal distances (see González-Varo et al. 2013) and, therefore, maximum altitudinal dispersal distances.

Second, the differences in the observed seed dispersal patterns between foxes and martens appear related with the habitat specificity of both species. The red fox is a habitatgeneralist species that can be found up to $4500 \mathrm{~m}$ above sea level, above the mountain tree 
line (Wilson and Mittermeier 2009), and that occupies forests, heathlands and farmlands across all the altitudinal levels of our study region (López-Bao and González-Varo 2011). In contrast, the pine marten is a forest-specialist species (Wilson and Mittermeier 2009, Balestrieri et al. 2016) and, indeed, its upper elevational limit throughout the western Palearctic is the limit of deciduous and conifer forests (e.g. up to $2300 \mathrm{~m}$ in the Pyrenees; Herrero et al. 2016). As previously mentioned, forest occupies approximately $50 \%$ of the territory in the study region and is usually limited to altitudes below $\sim 1400 \mathrm{~m}$ (Fig. S3). Hence, the upper limit of the seeds mobilized by the martens basically reflects the upper limit of the forest (see Fig. 1A). This is demonstrated by our finding that the vast majority of marten scats $(94 \%)$ were found in forest habitats and only a minor fraction was found in nonforest habitats $(6 \%)$. Forest dependence in pine martens can also explain why they dispersed seeds through steeper slopes because, in our study area, forests are mostly confined to the steepest hillsides below 1400 m (see Fig. S1; see also Fig. 1 in López-Bao and GonzálezVaro 2011). Conversely, habitat generalism could explain why the histogram for the red fox is slightly skewed towards higher elevations (Fig. 1A), with a peak between 1400 and 1500 $\mathrm{m}$, just around the forest limit, in areas where this generalist species can benefit from foraging in different habitat types. In fact, habitat diversity has been reported to be higher within the home range of red foxes than at the landscape scale (Cavallini and Lovari 1994). Accordingly, fox scats were more evenly distributed between forest (43\%) and non-forest habitats (57\%), as found in other systems (e.g. Rost et al. 2012). These results demonstrate that habitat generalism is necessary to transport seeds above vegetation belts that delimit contrasting habitat types, in the same way it is in fragmented landscapes for seed dispersal beyond the remnant vegetation (González-Varo et al. 2017). Therefore, our findings provide evidence that habitat specificity of seed dispersers is a critical trait in the context of altitudinal range expansions. 
2009), and their occurrence in natural and anthropogenic landscapes (López-Bao and

González-Varo 2011, Balestrieri et al. 2016), suggest that the patterns reported here are likely

to be common in other mountainous regions as well. Only in our study area, foxes and martens disperse the seeds of, at least, 14 fleshy-fruited plant species (López-Bao et al. 2015).

Therefore, these mammals, and their close relatives, may be helping hundreds of plant species to escape global warming across continents and biomes (Willson 1993, Koike et al. 2008, Rosalino and Santos-Reis 2009, González-Varo et al. 2015). More importantly, our study reveals two disperser traits that allow generalization beyond the studied animals: home range size and habitat specificity. We propose the use of both traits as a baseline to infer altitudinal seed dispersal mediated by other animal taxa, thereby as the starting hypotheses for future studies on this topic. Specifically, we hypothesize a more important role of longdistance seed dispersal in regions where mountains have shallow slopes, and a more landscape attributes can be combined to forecast climate-driven altitudinal range shifts. English grammar and style. We are also grateful for insightful suggestions from Axios 
was funded by the Galician Regional Government (project PGIDIT 05RFO 20001 PR). JPGV

Cierva' research contract (JCI-2012-13066) from the Spanish Ministry of Economy and

Competitiveness.

\section{References}

Balestrieri, A., et al. 2016. Modelling the distribution of forest-dependent species in humandominated landscapes: patterns for the pine marten in intensively cultivated lowlands. - PLoS ONE 11: e0158203.

Burnham, K. P. and Anderson, D. R. 2002. Model Selection and Multimodel Inference: A

Cavallini, P. and Lovari, S. 1994. Home range, habitat selection and activity of the red fox in a Mediterranean coastal ecotone. - Acta Theriologica 39: 279-287.

Cavallini, P. 1996. Variation in the social system of the red fox. - Ethol. Ecol. Evol. 8: 323342.

Chen, I.-C., et al. 2011. Rapid range shifts of species associated with high levels of climate warming. - Science 333: 1024-1026.

Colwell, R. K., et al. 2008. Global warming, elevational range shifts, and lowland biotic 329 attrition in the wet tropics. - Science 322: 258-261.

330 Corlett, R. T. and Westcott, D. A. 2013. Will plant movements keep up with climate change? 331 - Trends Ecol. Evol. 28: 482-488.

332 Cunze, S., et al. 2013. Are plant species able to keep pace with the rapidly changing climate? 333 - PLoS ONE 8: e67909.

334 De Marinis, A. M. and Masseti, M. 1995. Feeding habits of the pine marten Martes martes 335 L., 1758, in Europe: a review. - 1995 7: 143-150.

336 Dekker, J. J. A., et al. 2001. A spatial analysis of a population of red fox (Vulpes vulpes) in 337 the Dutch coastal dune area. - J. Zool. 255: 505-510. 
Dennis, A. and Westcott, D. A. 2007. Estimating dispersal kernels produced by a diverse community of vertebrates. - In: Dennis, A., et al. (eds.), Seed dispersal: theory and its application in a changing world. CAB International, pp. 201-228.

Devictor, V., et al. 2012. Differences in the climatic debts of birds and butterflies at a continental scale. - Nature Clim. Change 2: 121-124.

Dobrowski, S. Z. 2011. A climatic basis for microrefugia: the influence of terrain on climate. - Global Change Biol. 17: 1022-1035.

González-Varo, J. P., et al. 2013. Functional diversity among seed dispersal kernels generated by carnivorous mammals. - J. Anim. Ecol. 82: 562-571.

González-Varo, J. P., et al. 2015. Frugivory and seed dispersal by carnivorous mammals: functional traits. - Revista Ecosistemas 24: 43-50.

González-Varo, J. P., et al. 2017. Unravelling seed dispersal through fragmented landscapes: Frugivore species operate unevenly as mobile links. - Mol. Ecol. 00: 000-000.

Hampe, A. 2011. Plants on the move: The role of seed dispersal and initial population establishment for climate-driven range expansions. - Acta Oecol. 37: 666-673.

Harestad, A. S. and Bunnel, F. L. 1979. Home range and body weight - a reevaluation. Ecology 60: 389-402.

Herrera, C. M. 1989. Frugivory and seed dispersal by carnivorous mammals, and associated fruit characteristics, in undisturbed Mediterranean habitats. - Oikos 55: 250-262.

Herrero, J., et al. 2016. Martes martes. The IUCN Red List of Threatened Species, p. e.T12848A45199169.

Jordano, P., et al. 2007. Differential contribution of frugivores to complex seed dispersal patterns. - Proceedings of the National Academy of Sciences of the United States of America 104: 3278-3282.

Jordano, P. 2013. Fruits and frugivory. - In: Gallagher, R. S. (ed.) Seeds: the ecology of regeneration of plant communities. CABI, pp. 18-61.

Jump, A. S., et al. 2009. The altitude-for-latitude disparity in the range retractions of woody species. - Trends Ecol. Evol. 24: 694-701.

Koike, S., et al. 2008. Frugivory of carnivores and seed dispersal of fleshy fruits in cooltemperate deciduous forests. - Journal of Forest Research 13: 215-222. 
Koike, S., et al. 2011. Estimate of the seed shadow created by the Asiatic black bear Ursus thibetanus and its characteristics as a seed disperser in Japanese cool-temperate forest. Oikos 120: 280-290.

Lee-Yaw, J. A., et al. 2016. A synthesis of transplant experiments and ecological niche models suggests that range limits are often niche limits. - Ecol. Lett. 19: 710-722.

Lenoir, J. and Svenning, J. C. 2015. Climate-related range shifts - a global multidimensional synthesis and new research directions. - Ecography 38: 15-28.

López-Bao, J. V. and González-Varo, J. P. 2011. Frugivory and spatial patterns of seed deposition by carnivorous mammals in anthropogenic landscapes: a multi-scale approach. PLoS One 6: e14569.

López-Bao, J. V., et al. 2015. Mutualistic relationships under landscape change: Carnivorous mammals and plants after 30 years of land abandonment. - Basic Appl. Ecol. 16: 152-161.

McConkey, K. R., et al. 2012. Seed dispersal in changing landscapes. - Biol. Conserv. 146: 113.

Moreno-Opo, R., et al. 2015. Is it necessary managing carnivores to reverse the decline of endangered prey species? Insights from a removal experiment of mesocarnivores to benefit demographic parameters of the Pyrenean capercaillie. - PLOS ONE 10: e0139837.

Munilla, I., et al. 2008. Long-term changes in the breeding bird assemblages of two woodland patches in northwest Spain. - Ardeola 55: 221-227.

Naoe, S., et al. 2016. Mountain-climbing bears protect cherry species from global warming through vertical seed dispersal. - Curr. Biol. 26: R315-R316.

Nathan, R., et al. 2011. Spread of North American wind-dispersed trees in future environments. - Ecol. Lett. 14: 211-219.

Neilson, R. P., et al. 2005. Forecasting regional to global plant migration in response to climate change. - Bioscience 55: 749-759.

Ozinga, W. A., et al. 2009. Dispersal failure contributes to plant losses in NW Europe. - Ecol. Lett. 12: 66-74.

Parmesan, C. 2006. Ecological and evolutionary responses to recent climate change. - Annual Review of Ecology, Evolution, and Systematics 37: 637-669.

Pearson, R. G. 2006. Climate change and the migration capacity of species. - Trends Ecol. Evol. 21: 111-113. 
399 Pérez-Méndez, N., et al. 2016. The signatures of Anthropocene defaunation: cascading 400 effects of the seed dispersal collapse. - Scientific Reports 6: 24820.

401 Rosalino, L. M. and Santos-Reis, M. 2009. Fruit consumption by carnivores in Mediterranean 402 Europe. - Mamm. Rev. 39: 67-78.

403 Rost, J., et al. 2012. Seed dispersal by carnivorous mammals into burnt forests: An 404 opportunity for non-indigenous and cultivated plant species. - Basic Appl. Ecol. 13: 623-630.

405 Schloss, C. A., et al. 2012. Dispersal will limit ability of mammals to track climate change in 406 the Western Hemisphere. - Proceedings of the National Academy of Sciences 109: 86064078611.

408 Spiegel, O. and Nathan, R. 2007. Incorporating dispersal distance into the disperser 409 effectiveness framework: frugivorous birds provide complementary dispersal to plants in a 410 patchy environment. - Ecol. Lett. 10: 718-728.

411 Suárez-Esteban, A., et al. 2013. Barriers or corridors? The overlooked role of unpaved roads 412 in endozoochorous seed dispersal. - J. Appl. Ecol. 50: 767-774.

413 Willson, M. F. 1993. Mammals as seed-dispersal mutualists in North America. - Oikos 67: 414 159-176.

415 Wilson, D. E. and Mittermeier, R. A. 2009. Handbook of the mammals of the world. Vol. 1. 416 Carnivores. - Lynx Editions.

417 Zalewski, A., et al. 2004. Mobility and home range use by pine martens (Martes martes) in a 418 Polish primeval forest. - Ecoscience 11: 113-122. 
Table 1. Summary statistics of altitude of seed deposition and altitudinal seed dispersal distances mediated by red foxes and pine martens.

\begin{tabular}{|c|c|c|c|c|c|c|c|c|}
\hline \multirow[b]{2}{*}{ Disperser species } & \multicolumn{4}{|c|}{ Altitude of seed deposition (m) } & \multicolumn{4}{|c|}{ Altitudinal dispersal distance $(\mathrm{m})$} \\
\hline & Mean & Median & Min. & Max. & Mean & Median & Min. & Max. \\
\hline Red fox & 1382 & 1378 & 910 & 1580 & 26 & 31 & -465 & 288 \\
\hline Pine marten & 1253 & 1260 & 831 & 1546 & -67 & -30 & -438 & 255 \\
\hline
\end{tabular}


Table 2. Results of the linear models relating altitudinal seed dispersal distance to Euclidean dispersal distance and disperser species (red fox or pine marten). Note that model incorporating the disperser species had a better predictive power $(+15.6 \%)$ and was more informative $(\triangle \mathrm{AIC}=34)$.

\begin{tabular}{lccccc}
\hline Model: Altitudinal distance $\sim$ & $\mathrm{R}^{2}$ & AIC & Variables & $F$ & $P$ \\
\hline Euclidean distance & 0.465 & 1267.1 & Euclidean & 90.4 & $<0.001$ \\
& & & & & \\
& & & & & \\
& & & Euclidean & 127.6 & $<0.001$ \\
& & & Disperser & 17.4 & $<0.001$ \\
& & & Euclidean $\times$ Disperser & 26.6 & $<0.001$ \\
& & & & & \\
\end{tabular}


Figure 1. Altitudinal seed dispersal patterns mediated by red foxes and pine martens. (A) Altitudinal distribution (\%) of scats from red fox (left) and pine marten (right) containing colour-coded seed mimics ( $n=63$ and 32 scats containing 451 and 206 seed mimics, respectively). Dotted lines denote the altitudinal range of the feeding stations (i.e. the simulated 'source trees' of the seed mimics); solid lines denote the median altitude of the feeding stations belonging to the seeds dispersed by each species; red lines denote the maximum altitude in the study area. The forest limit in the study area is at $1400 \mathrm{~m}$ altitude. (B) Distribution (\%) of altitudinal dispersal distances, i.e. the altitudinal difference between the source and deposition sites of dispersed seed mimics ( $n=70$ and 34 dispersal events). The colour gradient is associated to $100-\mathrm{m}$ altitudinal intervals in order to illustrate seed dispersal events towards colder and warmer ranges.
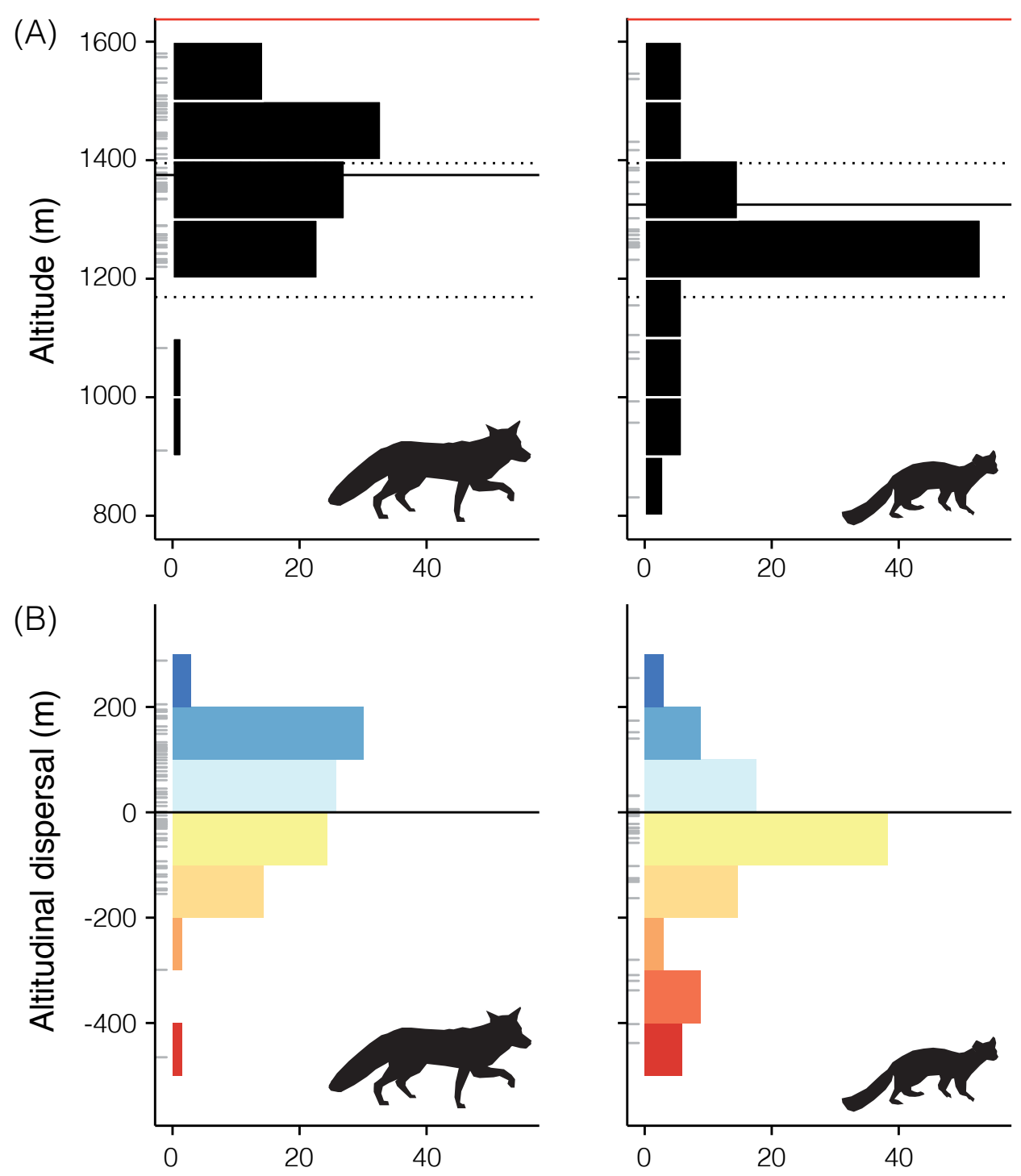

Frequency (\%)

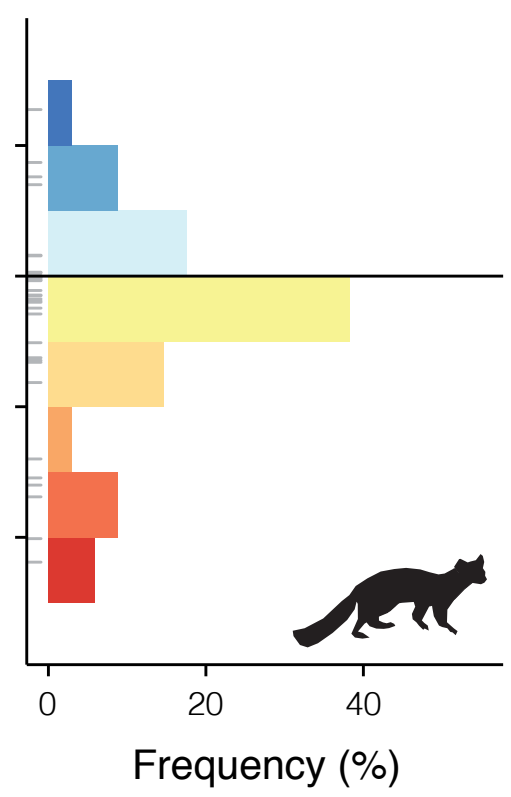


Figure 2. Relationships between horizontal (Euclidean) and altitudinal seed dispersal distances mediated by red foxes (circles, $n=70$; solid line: $y=25.7+0.064 x$ ) and pine martens (triangles, $n=34$; dotted line: $y=-24.6+0.140 x$ ). As in Fig. 1B, the colour gradient is associated to $100-\mathrm{m}$ altitudinal intervals in order to illustrate seed dispersal events towards colder and warmer ranges.

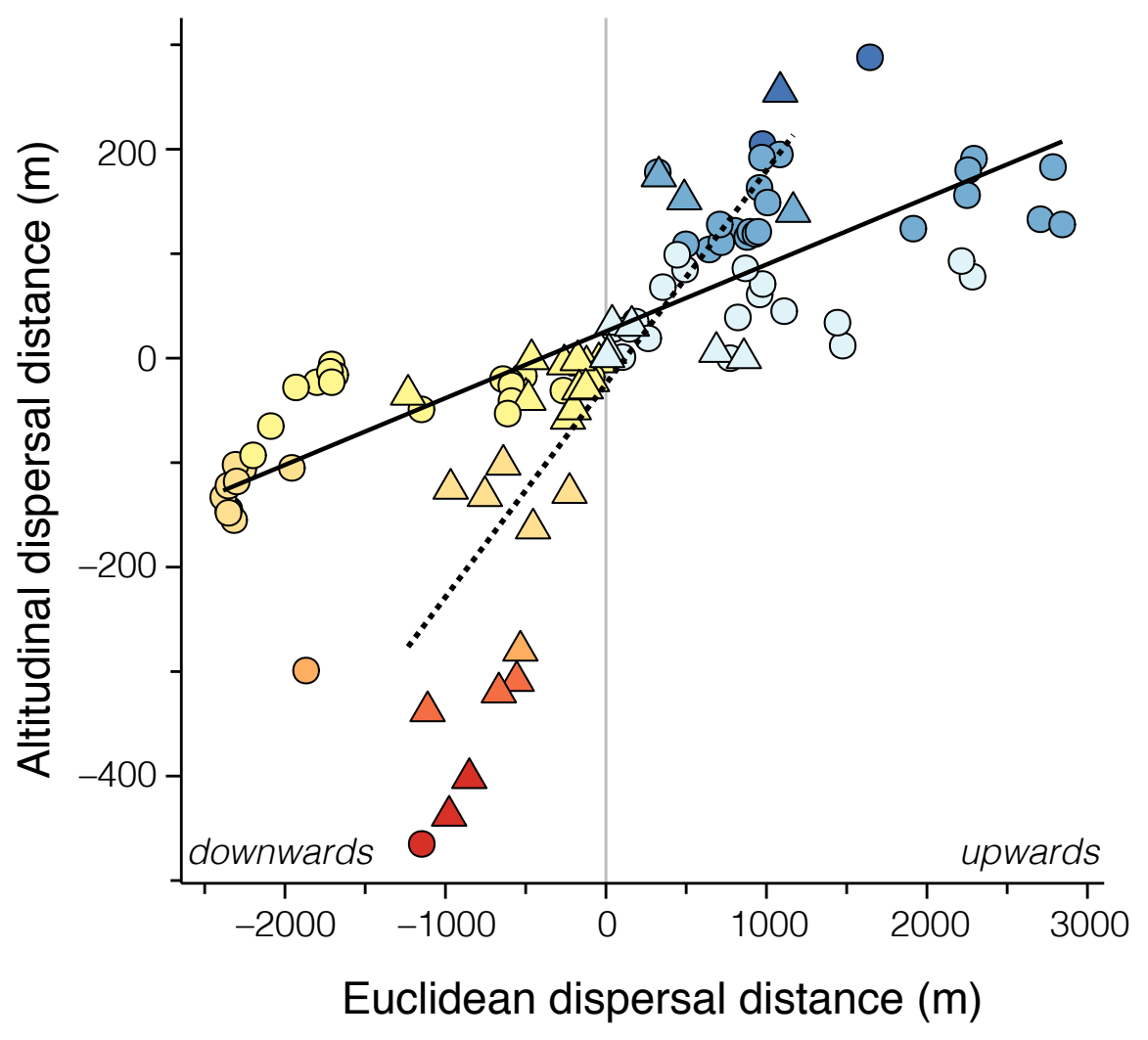

